\title{
Social Networks and Knowledge Transfer in Technological Park Companies in Brazil
}

\author{
Clarissa Mussi', Maria Terezinha Angeloni², Rafael Avila Faraco ${ }^{3}$
}

\begin{abstract}
This paper aims to propose a framework for a digital social network designed to support the knowledge transfer for innovation among companies located in a Technology Park of Florianópolis, in the Brazilian state of Santa Catarina. From a methodological point of view, the study is characterized by a qualitative approach and it was developed in three phases: (I) definition of the assumptions, requirements, functionalities and strategies for use of the social network; (2) development of the prototype for the social network and; (3) focus group sessions. The research data were analyzed using content analysis techniques. As for the results, this paper identifies four main pillars for the conception of digital social networks in the context of the technology park: types of knowledge; transmitters and receivers of knowledge, context for knowledge transfer and the nature of the knowledge transfer.
\end{abstract}

Keywords: knowledge transfer; digital social networks; technology park; innovation.

Universidade do Sul de Santa Catarina - PPGA - UNISUL. Av. José Acácio Moreira, 787, 88704-900. Phone: +55 48362 I 324 I

E-mail: 'Clarissa.mussi@unisul.br (principal contact for correspondence)

ISSN: 07 I8-2724. (http://www.jotmi.org)

Journal of Technology Management \& Innovation (c) Universidad Alberto Hurtado, Facultad de Economía y Negocios. 


\section{Introduction}

Business centers are characterized by networks of social relationships that connect and cluster businesses and individuals within a defined geographical region. This feature is important in a context in which innovation is increasingly a joint effort, occurring more rarely in isolated firms (Breschi, 2000). Different types of centers have different social structures and, consequently, different social networks; these idiosyncratic geographical regions may favor or hinder the transfer of knowledge between firms. In other words, it seems possible that certain factors may lead some business centers to be more innovative than others.Among these factors, relationship networks may play a key role (Teece, 2000) when it comes to innovation (Mcgrath,Tsai,Venkataraman \& MacMillan, 1996).

If, on one hand, there are no widely accepted criteria or general rules for determining whether or not a company is innovative or what makes one technology park more innovative than another - since there are variations on many factors, such as the configuration of the companies, the types of bonds which link businesses, relationships with external entities such as universities, research centers and other companies (Romijn \& Albu, 2002) - on the other, there is consensus that business centers advance the creation and availability of knowledge, generating innovation (Lalkaka, 2002). Szulanski (1996) points out that geographical proximity facilitates the flow of knowledge within technological parks and enables social relationship networks to promote the transfer of knowledge and learning opportunities, the aspects necessary for developing innovations.

Recent studies have highlighted the role of social networks and social media in the transfer of knowledge within an organization (intra-organization) and/or between different organizations (inter-organization) (Von Krogh, 2012; Bebensee, Helms \& Spruit, 20I I; Faraj, Jarvenpaa \& Majchrzak., 20II; Haefliger, Monteiro, Foray \& Von Krogh, 20II). In this sense, it is assumed that a digital social network can be developed with the goal of fostering collaboration between organizations in business incubators and parks, and ultimately, of knowledge transfer and innovation. As noted by von Krogh (20I2), social software extensively facilitates knowledge sharing between individuals within and across organizational boundaries, as it allows many types of content to evolve through a variety of collaborative processes.

Given the above, the problem that guided this research was: how can one configure a digital social network which leverages the transfer of knowledge for innovation among technology-based companies located in Brazil's technology parks?
In this research, the technology park in question is located in the southern region of the state of Santa Catarina. With over 300 companies, it generates about 10 thousand direct jobs and constitutes a society whose main feature is the value of knowledge as a catalyst for its own development. The main contributions of the study are to be found at the intersection of the themes of social relationship networks, knowledge management and innovation, and new information and communication technology. Thus, we expect this research to provide the technology-based entrepreneur with greater opportunities for innovation, which significantly affects the generation of jobs and opportunities.

Methodologically, the research was organized into three phases: the first, based on the theoretical foundations of the proposed themes, includes the definition of assumptions, requirements, features and strategies for use of a digital social network in order to support the transfer of knowledge within the technology park; the second involves the development of a prototype of this social network; and the third phase aims to assess and discuss the results generated in the previous stages through the methodology of focus groups.

This article is organized into four sections, in addition to this introduction. The first section presents the theoretical framework of the study; the second addresses the research methodology adopted; the third presents the results of the research, and the fourth and final section presents conclusions and recommendations for future studies.

\section{Theoretical framework}

The theoretical framework includes the transfer of knowledge for innovation, digital social networks and the channels of knowledge transfer.

\section{Transfer of knowledge for innovation}

Several studies highlight the significant influence of knowledge transfer in the innovative capacity of organizations. Cordey-Hayes and Gilbert (1996) discuss knowledge transfer as a means by which organizations can implement innovations. Vito, Garavello and Schiuma (1999) see knowledge transfer as a strategy for achieving competitive advantage, so organizations can respond to change and innovate. Knudsen (2007), exploring different types of relationships between companies to develop new products, identified that the process of knowledge transfer influenced innovation.

Knowledge transfer involves, firstly, the preparation and delivery of knowledge to a potential receiver and, secondly, the acquisition / absorption of this knowledge by the receiver (Bröchne, Rosander \& Waara, 2004). Moreover, the joint transmission and absorption have no value if the acquired knowledge is not put to use (Davenport and Prusak,

ISSN: 07 I8-2724. (http://www.jotmi.org)

Journal of Technology Management \& Innovation (c) Universidad Alberto Hurtado, Facultad de Economía y Negocios. 
1998). Knowledge transfer can occur between different "entities": individuals, teams, intra-organizational units, organizations, and even inter-organizational networks (Hackney, Desouza, \& Loebbecke, 2005; Lawson, Petersen, Cousins \& Handfield, 2009).

Regarding the transfer of inter-organizational knowledge, the focus of this article, Comi and Eppler (2010) point out that organizations continually seek opportunities for innovation beyond their organizational boundaries, thus engaging in inter-organizational collaborations. Sources of innovation are not found exclusively within companies, but also at the interfaces between companies, universities, research laboratories, suppliers and customers (Lawson et. al., 2009). Inter-organizational knowledge networks represent opportunities for individuals to engage in new forms of cooperative learning, as well as opportunities for organizations to better achieve their goals through the acquisition of knowledge critical to their processes or strategy, or through collaborative knowledge exchanges and initiatives (Hackney et. al., 2005).

Regardless of the context in which it occurs, be it intraorganizational or inter-organizational, knowledge transfer per se is a process influenced by many factors or variables. As O'Dell and Grayson (1998) say, the natural desire that most people have to learn and share what they know may be frustrated by a variety of barriers. In this sense, when one intends to encourage the transfer of knowledge, it becomes necessary to pay attention to the factors that may facilitate, hinder or prevent individuals from sharing what they know. In general, these factors are related to:

a) knowledge itself - the difficulty in transferring knowledge is directly related to the type of knowledge involved, either explicit or implied. (Matin, Alvani, Jandaghi \& Pashazadeh, 2010; Davenport \& Prusak, 1998; Nonaka \& Takeuchi, 1995); b) the transmitter and receiver of knowledge - the existence of a common language between the sharing agents; the capacity of the receiver for absorbing knowledge, in other words, the receiver's ability to acquire and use it; the perceived value of the source's knowledge, and; motivation - of the source to transfer knowledge and of the receiver to acquire it. (Matin et. al., 2010; Tonet \& Paz, 2006; Gupta \& Govindarajan, 2000; Davenport \& Pruzak, 1998);

c) the context (environment) of sharing knowledge - variables of the organizational environment that may, depending on how they are configured, influence knowledge transfer activities: organizational structure (formality, complexity, focus), organizational culture (organizational and social aspects), information technology (IT skills), capital structure (structural network aspects, cognitive and communication aspects), behavioral aspects (political behavior); aspects of knowledge protection (Matin et. al., 2010; Tonet \& Paz, 2006; Gupta \& Govindarajan, 2000; von Krogh, 20I2);

d) the nature of the transfer - intra-organizational or interorganizational. (Lahti, 2000; Lam, 1997, Von Krogh, 20 I2).

Many of the factors listed above (a, b and c) are also demonstrated when it comes to inter-organizational knowledge transfer (d). With regard to the type of knowledge being transferred, tacit knowledge is more easily and frequently passed between individual members of the same organization because they share a common working environment and also common experiences and values, while in situations where knowledge sharing involves individuals belonging to different organizations, explicit knowledge will be shared, because this type of knowledge can be easily documented (Lahti, 2000; Lam, 1997).

Pointing to the challenges and solutions concerning the inter-organizational transfer of knowledge, Comi and Eppler (2010) emphasize that barriers may be encountered due to organizational differences such as those related to management styles, the culture and power bases of the participating organizations, as well as those of a semantic nature, such as the lack of a common language, i.e. comprehension problems arising from the multidisciplinary nature of inter-organizational work.

Comi and Eppler (20I0) suggest that barriers may be related to the protection of proprietary knowledge from unintentional leaks between collaborating partners, resulting in lack of confidence. Similarly, Hackney et. al. (2005) address issues related to cooperation and competition in the process of knowledge transfer in inter-organizational networks. The question of the strategic role of knowledge in organizations and its protection, specifically in the context of online social networks, is discussed by von Krogh (2012). As the authors argue, in contrast to traditional knowledge management in which access to knowledge repositories is centrally governed, when it comes to knowledge transfer through social networks, access to content and its distribution are more decentralized - it is the individual who chooses with whom and what to share.

In the context of inter-organizational cooperation for innovation, the role of online social networks has been highlighted - they may be seen as tools that support the transfer of knowledge (Von Krogh, 20I2; Bebensee et. al., 20 I I, Faraj et. al., 20I I).This is the subject of the following section. 


\section{Digital social networks and channels of knowledge transfer}

In the study of organizations, the term network is used to describe many types of economic arrangement, such as vertical networks that integrate various links in the supply chain, clusters, joint ventures and strategic alliances. Another form of interconnection between companies is virtual organizations, which break the barriers of space and time, giving rise to global organizations (Castells, 2003). Porter (1998) and Teece (2000) agree that among the different ways organizations generate competitive advantages, the formation of social networks is one of the most promising.

The popularization of the Internet has been responsible for important changes in society. For this study, the most significant of these changes is the possibility of expression and socialization by means of computer-mediated communication tools (Castells, 2003). This communication is based on the structures of what has come to be known as Web 2.0. Web 2.0 is the basic structure that enables the use of electronic and communication resources for the formation, maintenance or representation of social relationships, the so-called digital social networks.

Bebensee et. al. (20II) argue that online social networks are changing the way individuals share knowledge. These networks, by means of Web 2.0 features, are relevant to processes of knowledge management such as the acquisition, creation and transfer of knowledge, mainly because: they are based on principles of a social nature; applications are intuitive and easy to use (e.g. blogs, wikis, social bookmarking); they are based on open platforms.

Digital social networks have channels that enable information and knowledge to be transferred between their participants. In the context and literature of social networks, these channels used for relationships between individuals are commonly called social tools or social media, with the networks being, effectively, the set of relationships supported by these media. The transfer of knowledge can be achieved through informal channels or media (spontaneous, unstructured exchanges) or formal ones (more structured and formalized transfers); personal channels (e.g. personal contacts, internships) or impersonal channels (e.g. forums afforded by electronic tools, repositories of knowledge based on IT) (Alavi \& Leidner, 200I; Davenport \& Prusak, 1998).

Organizations can benefit from online social networks and social media by their presence in different areas. Among the various organizational activities that can benefit from the introduction of digital social networks, in the context of this work, the transfer of knowledge and innovation stands out.
The way many organizations have faced the challenges raised by the constant need for innovation involves the introduction of models of flexibility and intense collaboration with external agents (Almirall \& Casadesus-Masanell, 2010). The creation and maintenance of social ties between firms and other agents can respond to this need for ongoing interaction.

Based on concepts inherent to the transfer of inter-organizational knowledge for innovation and to digital social networks, as well as on the potential of these networks to establish social ties between different agents and organizations, a set of assumptions has been outlined in order to develop a social network for the transfer of knowledge and innovation within technology parks, according to the methodology described in the next section.

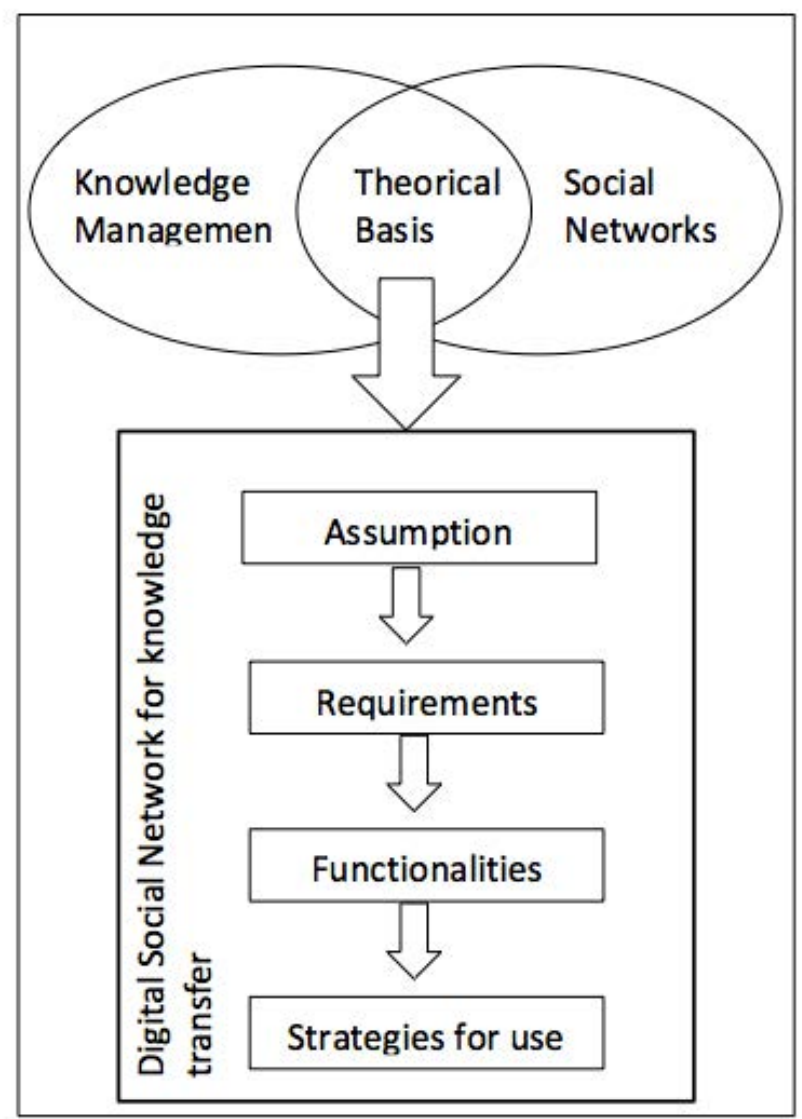

Figure I - Outline of the first phase of research. Source: prepared by the authors (2014) 


\section{Methodology}

This research, in accordance with its methodological approach, is qualitative (Yin, 2009). The development of the study comprises the following three phases: (I) definition of the assumptions, requirements, features and strategies of the network; (2) development of a prototype of the network; (3) focus groups.

\section{Phase one: definition of assumptions, requirements, features and strategies}

The first phase consists of theoretical research that provides the bases for the development of a set of theoretical assumptions for the digital social network, in accordance with the outline shown in Figure I. Minayo (2000, p. 93) highlights that, under the qualitative approach, the term "assumptions" is generally used to express basic parameters that serve as a path and support in the interaction with empirical reality.

The definition of theoretical assumptions guided the survey of the network requirements, features and strategies for use. Four assumptions were then outlined for a digital social network with the potential to support knowledge transfer for innovation among incubated companies within a technology park. The assumptions are based on the factors that may facilitate, hinder or prevent the transfer of knowledge, related to: a) knowledge itself; b) the transmitter and receiver of knowledge; c) the context (environment) of sharing knowledge and d) the nature of the transfer.These factors and the major authors are shown in Table I.

From each of the theoretical assumptions, requirements, features and strategies of network usage were derived, which lay the groundwork for the development of the first version of the social network's prototype.Thus, for each assumption, requirements were derived, for each requirement, features were derived and for each feature, strategies of network usage were derived. By assumption, a more general/comprehensive preconceived notion is understood; by requirements, the specific conditions in which the assumptions can be met; by feature, the functions to be implemented in order to meet requirements; and by usage strategies, the features' forms of use within the technology park, i.e. in the context of the network.

\section{Phase two: prototyping}

In this phase, a prototype of a digital social network was developed, which aimed to facilitate discussions held in the focus group meetings (third phase). The approach to prototyping of systems in the field of software engineering has gained momentum with the emergence of tools that accelerate the process of software development. One objective of this approach is to facilitate the survey and validation of requirements with users of systems, thus permitting fewer risks when defining the scope of a software project, especially in cases where there is a wide range of users (Boehm et. al., 1988).A prototype is therefore characterized as a model or an initial version of a system with the aim of exploring needs and finding out more about problems and possible solutions (Sommerville, 2004).

The developed prototype did not aim to turn into a final product, but rather it aimed to enable, within the context of the focus group meetings, the generation of a set of recommendations for the implementation of a digital social network with the intention of stimulating the transfer of knowledge for innovation between technology-based companies. To develop the prototype of the network, an open source platform for social networks called Elgg was used. (available at http://www.elgg.org).

\begin{tabular}{|l|l|}
\hline Subject of the assumption & Major authors \\
\hline Types of knowledge - tacit and explicit & $\begin{array}{l}\text { Matin et. al. (2010), Tonet \& Paz (2006), Nonaka \& } \\
\text { Takeuchi (1995), Davenport \& Prusak (1998). }\end{array}$ \\
\hline Profile of receivers and transmitters of knowledge & $\begin{array}{l}\text { Matin et. al. (20I0), Tonet \& Paz (2006), Gupta \& } \\
\text { Govindarajan (2000), Davenport \& Prusak (1998). }\end{array}$ \\
\hline Context of knowledge transfer & $\begin{array}{l}\text { von Krogh (20I2); Matin et. al. (20 I0), Tonet and Paz } \\
\text { (2006), Gupta \& Govindarajan (2000), Davenport \& } \\
\text { Prusak (1998), Nonaka \& Takeuchi (1995). }\end{array}$ \\
\hline Nature of knowledge transfer - internal or external & $\begin{array}{l}\text { von Krogh (20I2), Comi \& Eppler (20 I0), Hackney; } \\
\text { Desouza \& Loebbecke (2005), Lahti (2000), Lam } \\
\text { (1997). }\end{array}$ \\
\hline
\end{tabular}

Table I - Subject of theoretical assumptions and major authors

ISSN: 07 I8-2724. (http://www.jotmi.org)

Journal of Technology Management \& Innovation (c) Universidad Alberto Hurtado, Facultad de Economía y Negocios. 


\section{Phase three: focus groups}

The third phase involves the validation of the assumptions, requirements, features and strategies defined in the first phase, as well as the prototype structured and implemented in the second phase through focus group workshops. The focus group methodology is considered to be a technique for collecting qualitative information from primary sources, which can help in assessing the needs of the users before the design of the interface and after its implementation (O'heocha, Wang \& Conboy, 20I2).

Two focus group workshops were held in November 2012. They were recorded and consisted of three teams (A, B and $C)$. In the first workshop, team $A$ consisted of the researchers and authors of this article, one of which was a moderator; the second team (team B) consisted of two individuals from the company hired to develop the prototype and the third team (team C) consisted of six evaluators of the assumptions, requirements, features and strategies and of the social network prototype. The second workshop consisted of the same members of teams $A$ and $B$, and another five evaluators of the work undertaken, as shown in Table 2.

The definition of the participants of the focus groups was done intentionally, bringing together teachers of undergraduate and postgraduate courses in the subject areas of this research and entrepreneurs in the field of information technology, meeting the requirement of diversity of participant profiles in each focus group. All participants had some level of participation in the technology park in question. At the beginning of each workshop, all the participants introduced themselves. Then, the research, its aims and methodological steps, were presented. Orientation on how a focus group works and its aims was also provided. Issues for discussion were then proposed.The first issue presented for discussion was the question (the problem) that guided the development of this research. The participants were freely encouraged to express their opinions. Subsequently, the assumptions of the network were presented for discussion and, finally, the prototype.

The information from the focus group workshops was analyzed qualitatively by means of a process of categorization.
This procedure is characterized by the classification of elements into categories (codes or labels), bringing together a group of elements with common characteristics under a generic title (Saunders, Lewis \& Thornhill, 2009). The form of categorization used was mixed grid analysis. Preliminary categories are defined (closed grid), however during the process of analysis, new categories emerge (open grid), which can be added to those previously defined and may indicate the need for the subdivision, inclusion or exclusion of categories. Preliminary or predefined categories were derived from the theoretical assumptions and requirements defined for the social network. We started by performing a reading of the focus group workshops, transcribed in full from the recordings made, aiming to identify the preliminary categories/subcategories and/or the emergence of new categories/ subcategories. The categories analyzed are presented in Table 7. During the presentation of the results, in the following section, participants were identified by numbers as follows: PI to PII.

\section{Results}

The results of the research are organized according to the methodological phases: first phase results - the assumptions, requirements, features and strategies determined for the network (section 4.I); second phase results - characteristics of the network prototype's development process (section 4.2); third phase results - consolidated analysis of the focus group workshops (section 4.3).

\section{Assumptions, requirements, features and strategies for a digital social network for knowledge transfer}

The definition of theoretical assumptions guided the entire development of the digital social network. The first assumption of the social network is related to the different types of knowledge and the need to consider them in the context of inter-organizational knowledge transfer. In this sense, it becomes necessary to provide, within these networks, channels that support both the transfer of tacit knowledge and explicit knowledge. Therefore, the assumption was stated thus: Both types of knowledge - tacit and explicit - permeate the social network in contexts of formal and informal, personal and impersonal knowledge transfer.

\begin{tabular}{|l|l|l|}
\hline Workshops/participants & Workshop I & Workshop 2 \\
\hline Research team & 4 & 4 \\
\hline IT company team & 2 & 2 \\
\hline Participants & 6 & 5 \\
\hline Total number of participants & 12 & II \\
\hline
\end{tabular}

Table 2 - Description of focus groups. Source: prepared by the authors (2014)

ISSN: 07I 8-2724. (http://www.jotmi.org)

Journal of Technology Management \& Innovation (c) Universidad Alberto Hurtado, Facultad de Economía y Negocios. 
Two requirements were outlined for this assumption, the first relating to channels for transferring tacit knowledge and the second explicit knowledge, described as follows: a) the network should provide channels which enable the transfer of tacit knowledge; b) the network should provide channels which enable the transfer of explicit knowledge.

For each requirement, the features and the strategies for the use of these features, were proposed within the context of technology parks, as illustrated in table 3.

The second assumption of the social network relates to the stakeholders in the transfer of knowledge and to the influence of their profile in the exchanges of knowledge that are established, described thus: the transfer of knowledge in the social network is influenced by factors related to the stakeholders in the network: receivers and transmitters of knowledge.

Two requirements were created for this assumption: the first is related to questions of the identification and ranking of participants on the network and the second to the provision of mechanisms that permit the recognition of participants by the whole community: a) the network should allow the transmitters and receivers of knowledge to be identified and to be ranked; b) the network should possess mechanisms for evaluating the relevance of the knowledge transferred.

Some examples of features and the strategies for the use of these features in technology parks, covering the requirements outlined, are illustrated in table 4.

The third assumption of the social network is related to the environment for transferring knowledge, more specifically to the context which permeates the transfer and the possibility of this context affecting the exchange of knowledge on the network. This assumption was phrased as follows: the organizational context (environment) exerts an influence on the transfer of knowledge on the network.

The requirements defined for this assumption relate to the provision of features that stimulate the exchange of knowledge as well as the usability of these features and the creation of mechanisms that seek to protect strategic knowledge. With this as the focus, the following requirements were defined: a) the network should provide the basis for the creation of a simplified, stimulating environment for the sharing of knowledge; b) the network should have mechanisms for protecting strategic knowledge.

A number of examples of features and strategies for use in technology parks, addressing this assumption and the respective requirements, are shown in table 5 .
The fourth assumption of the social network for the transfer of knowledge considers the nature of the transfer, i.e. if it is taking place between members of the same organization that participate in the network and/or between members of different organizations, described as follows: the transfer of knowledge on the network takes place by means of interactions originating within and/or outside of the organization.

In this regard, one requirement was established that focuses on mechanisms that qualify the origin of this knowledge and which permit the management of the knowledge flows involved in the transfer, as follows: the network should contain mechanisms to qualify the knowledge which is internal or external to the organization and also manage the flow of knowledge transfer between organizations. For this requirement, some examples of the features and strategies for use in technology parks are shown in table 6.

The assumptions, requirements, features and strategies defined and presented in tables 3 to 6 furnished support for the process of structuring and developing the digital social network prototype.

\section{Prototype: characteristics of development of the network prototype}

The principal software tool used for the network prototype was Elgg, an open-source platform for networks. Launched in 2004, Elgg is a tool that permits the creation of social networks, making available a host of features where it is fully possible to make alterations, as it is open source. So Elgg is not just a product created by a few developers but in fact a platform created and maintained on a continuous basis by a global community of users. While Elgg offers the advantages of flexibility and ease of access of an open- source software platform, the lack of support and documentation brought with it technical difficulties as regards the use of the tool's plug-ins.

The network prototype that was developed was integrated with the Facebook social network to facilitate the automatic search for data on the users who make up this network. Accordingly, the entire Facebook network of contacts and relationships could easily belong to the network created for the technology park. Figure 2 below shows the main screen of the network prototype, designated as the Konexa social network, that was proposed for the technology park in question.

On the left-hand side of the screen is the options menu, with the proposed functions discussed during the focus group meetings and established in phase I of the research study. Every time one of the features is clicked, a new window opens addressing the respective feature. In addition to 


\begin{tabular}{|c|c|}
\hline Assumption I & $\begin{array}{l}\text { Both types of knowledge - tacit and explicit - permeate the social network in formal and } \\
\text { informal, personal and impersonal knowledge transfer environments. }\end{array}$ \\
\hline Requirement I.I & The network should provide channels that enable the transfer of tacit knowledge. \\
\hline $\begin{array}{l}\text { Features and strategies } \\
\text { for use in the park }\end{array}$ & $\begin{array}{l}\text { Highly interactive features include: } \\
\text { Videoconferencing: this permits the simultaneous, interpersonal interaction (video and } \\
\text { sound) between two or more people. Holding of meetings, lectures, mini-courses, discus- } \\
\text { sion with specialists, hands-on activities, amongst the network's participants. } \\
\text { Chat - permits simultaneous, interpersonal communication similar to an actual conver- } \\
\text { sation. Conversations can take place between two or more staff members in a company } \\
\text { or between different companies. One of the ways to use the chat feature is in discussions } \\
\text { with specialists. } \\
\text { Virtual brainstorming - an area for public interaction for the resolution of predetermined } \\
\text { problems or the generation of innovation. It permits the free inclusion of suggestions and } \\
\text { ideas. It may be used whenever a user or organization needs a place to generate focused } \\
\text { ideas. } \\
\text { Talent or organizational skills database - system which permits the survey and storage of } \\
\text { the skills of those working in companies in the park and their partners. It allows for the } \\
\text { localization of expertise in the various incubated companies and the exchange of talent. } \\
\text { Forums - these provide interaction between those interested in a common subject. } \\
\text { Proposal by all users of topics of interest for the members of the network, for discus- } \\
\text { sion purposes. They may be used for: the exchange of ideas in groups, exposing common } \\
\text { problems and the search for solutions as well as the creation of new items of knowledge, } \\
\text { communities of practice (CoP). } \\
\text { Blue pages - register (catalogue) of specialists outside the area of the park, both individu- } \\
\text { als and legal entities, with their respective skills and the way to localize them (consultants, } \\
\text { ex-staff, retirees, etc.). Evaluation of companies that have already provided services to } \\
\text { companies in the park. } \\
\text { Search - search feature using keywords. }\end{array}$ \\
\hline Requirement I.2 & The network should provide channels that enable the transfer of explicit knowledge. \\
\hline $\begin{array}{l}\text { Features and strategies } \\
\text { of use in the park }\end{array}$ & $\begin{array}{l}\text { These are the features that can be formatted on media. } \\
\text { Founded on best practices - tool in which the best practices are stored for subsequent } \\
\text { viewing by network community. The best practices may be reused by the other compa- } \\
\text { nies and others may be generated within the network itself. The main information to be } \\
\text { registered includes: problems resolved using best practices, keywords, proposer, descrip- } \\
\text { tion of the best practice, useful features to show acceptance of the best practice. } \\
\text { FAQ (Frequently Asked Questions) - an area which brings together the answers to the } \\
\text { questions most frequently asked by members of the network concerning access, func- } \\
\text { tions and the use of the network itself. } \\
\text { WIKI - refers to the simplified, collaborative development of the various topics (con- } \\
\text { cepts) on the Web. Definition of subjects of common interest to the members of the } \\
\text { network. Based on the principles of folksonomy and self-regulation, it permits free } \\
\text { expression for all and facilitates the creation and transfer of knowledge.Any member can } \\
\text { create a new topic or subject. } \\
\text { Shared Bookmark - an area for sharing favorite web pages and websites for specific } \\
\text { topics. Each member is able to insert new bookmark topics. } \\
\text { Ideas database - a warehouse that permits the recording, tracking and evaluation of ideas } \\
\text { that may benefit and strengthen the park, as well as enterprising suggestions that permit } \\
\text { the generation of new business. The park community can submit ideas for new business } \\
\text { ideas which can then be evaluated and backed by companies or investors. } \\
\text { Virtual library - a warehouse of files in different formats (text, sounds, videos, etc.). File } \\
\text { sharing of books, podcasts, videos, course books, manuals, presentations, simulators. }\end{array}$ \\
\hline
\end{tabular}

Table 3 -Assumption I - Types of knowledge: tacit and explicit.

ISSN: 07 I8-2724. (http://www.jotmi.org)

Journal of Technology Management \& Innovation (c) Universidad Alberto Hurtado, Facultad de Economía y Negocios. 


\begin{tabular}{|c|c|}
\hline Assumption 2 & $\begin{array}{l}\text { The transfer of knowledge on the social network is influenced by factors related to the } \\
\text { network stakeholders: the receiver and transmitter of knowledge. }\end{array}$ \\
\hline Requirement 2.1 & $\begin{array}{l}\text { The network should allow the transmitters and receivers of knowledge to be identified } \\
\text { and to be ranked. }\end{array}$ \\
\hline $\begin{array}{l}\text { Features and strategies } \\
\text { of use in the park }\end{array}$ & $\begin{array}{l}\text { Network user profile - allows for the recording of information (identification of institu- } \\
\text { tion and individual, area of knowledge, areas of interest, professional experience, amongst } \\
\text { others) on network users who register their profiles and who can access the profiles of } \\
\text { other users on the network. } \\
\text { Participation of users on the network - queries or reports tracking the interaction carried } \\
\text { out on the network between sender and receiver of the knowledge. Users should know } \\
\text { what is their level of participation on the network both as transmitter and as receiver of } \\
\text { knowledge. Establishing mechanisms to reward the most active users and/or organizations } \\
\text { on the network (system to recognize and acknowledge the value of individuals who make } \\
\text { contributions to the transfer of knowledge). } \\
\text { Affinity - presents the users who have some affinity on account of their proximity in terms } \\
\text { of knowledge or interests. Each user has a list of other users with a profile similar to } \\
\text { theirs. The users can find other users with a potential to transfer knowledge, based on the } \\
\text { respective profiles. }\end{array}$ \\
\hline Requirement 2.2 & $\begin{array}{l}\text { The network should contain mechanisms for evaluating the relevance of the knowledge } \\
\text { transferred (as a result of these mechanisms, people can receive recognition from the } \\
\text { entire community). }\end{array}$ \\
\hline $\begin{array}{l}\text { Features and strategies } \\
\text { of use in the park }\end{array}$ & $\begin{array}{l}\text { Relevance of the knowledge transferred - Enables the relevance of posted content to be } \\
\text { highlighted. The "useful" function (similar to "like" on Facebook) indicating that the infor- } \\
\text { mation was important to some or other context.Valuing the network user as regards his/ } \\
\text { her contribution. The prize could be recognition as a relevant user or even some form of } \\
\text { recompense. Highlighting the "most useful" topics to the park community, thereby promot- } \\
\text { ing capacity-building events. }\end{array}$ \\
\hline
\end{tabular}

Table 4 - Assumption 2 - Profile of receivers and transmitters of knowledge

\begin{tabular}{|c|c|}
\hline Assumption 3 & $\begin{array}{l}\text { The organizational context (environment) exerts an influence on the transfer of knowledge } \\
\text { on the network. }\end{array}$ \\
\hline Requirement 3.1 & $\begin{array}{l}\text { The network should provide a basis for the creation of a simplified, stimulating environment } \\
\text { for the sharing of knowledge. }\end{array}$ \\
\hline $\begin{array}{l}\text { Features and strategies } \\
\text { of use in the park }\end{array}$ & $\begin{array}{l}\text { Analytical graphs of social networks - permit us to view the relationships between the mem- } \\
\text { bers and it is possible to detect the dynamics of interaction on the network. The viewing of } \\
\text { these dynamics can create mechanisms to stimulate use of the network. } \\
\text { Participation of organizations - area for demonstrating the participation of each organization } \\
\text { on the network and the relationships established between them, as well highlighting those } \\
\text { organizations with the more active users. Highlighting and/or rewarding organizations that } \\
\text { incentivize their staff to participate in the network. Creating periodic events to acknowledge } \\
\text { the value of the organizations or groups which are most engaged. } \\
\text { Good practices for stimulating use of the network - area for publicizing good practices for } \\
\text { incentivizing the use of the network. Organizations can formalize the "motivator" or "multi- } \\
\text { plier" users on the network. } \\
\text { Help - publicizes the features of the network and the ways to use it, and provides space for } \\
\text { suggestions on network improvement. New features of interest to the network users may be } \\
\text { developed and the existing ones perfected. }\end{array}$ \\
\hline Requirement 3.2 & The network should have mechanisms for protecting strategic knowledge. \\
\hline $\begin{array}{l}\text { Features and strategies } \\
\text { of use in the park }\end{array}$ & $\begin{array}{l}\text { Policy of network use - area for creating a network usage policy with topics for stimulating } \\
\text { participation, security and reliability, and to implement options for allowing complaints of } \\
\text { poor use of the network. Each organization could have one user responsible for monitoring } \\
\text { the network with regard to the usage policy. It could be the selfsame "motivator" user. }\end{array}$ \\
\hline
\end{tabular}

Table 5 - Assumption 3 - Profile of the receivers and transmitters of knowledge

ISSN: 07 I8-2724. (http://www.jotmi.org)

Journal of Technology Management \& Innovation (c) Universidad Alberto Hurtado, Facultad de Economía y Negocios. 
features for end-users, the network displays a panel with management options for the network as a whole.

\section{Focus groups: consolidated analysis}

The preliminary analysis categories and subcategories displayed in table 7 derive from the respective network assumptions and requirements presented in section 4.I (categories I to 4). During the analysis, new categories (categories 5 and 6) emerged from the debates of the focus group participants.

Although in agreement with the need for the network to offer means that afford both the transfer of explicit and tacit knowledge (category I), the participants did not appear to hold great concern for the distinction between these types of knowledge. However there was a clear reflection on how the network could lead to informal encounters, which the participants consider to be fundamental to the exchange of knowledge, particularly tacit knowledge, and the creation of knowledge, as the following statements illustrate:

I believe that it will be something of a challenge to introduce an environment that this company can benefit from. We have performed research on innovation and creativity and we have seen that the secret of innovation is the exchange of ideas on street corners, in the bars. This is going back to before creativity and innovation - a fostering environment where it is fun to exchange ideas, that security of being able to exchange ideas. $(\mathrm{PI})$

\begin{tabular}{|l|l|}
\hline Assumption 4 & $\begin{array}{l}\text { The transfer of knowledge on the network occurs by means of interactions originating within and/or } \\
\text { outside of the organization. }\end{array}$ \\
\hline Requirement 4.I & $\begin{array}{l}\text { The network should have mechanisms for qualifying knowledge within or outside of the organization } \\
\text { and also manage the flow of the knowledge transfer between organizations. }\end{array}$ \\
\hline $\begin{array}{l}\text { Features and strategies } \\
\text { of use in the park }\end{array}$ & $\begin{array}{l}\text { Organizational profile - permits the recording of information about organizations that use the net- } \\
\text { work, highlighting organizational skills. The organizations register their profile and users can access } \\
\text { the profile of all member organizations on the network } \\
\text { Analysis of message transfer flows - this enables the flow of messages to be mapped within an orga- } \\
\text { nization or between different organizations. Checking of the concentration of internal and external } \\
\text { transfers of knowledge. Possibility of drilling down into relationships detected by the map. Identifica- } \\
\text { tion of organizations with greater knowledge in particular areas. }\end{array}$ \\
\hline
\end{tabular}

Table 6 - Assumption 4 - Context for the transfer of knowledge

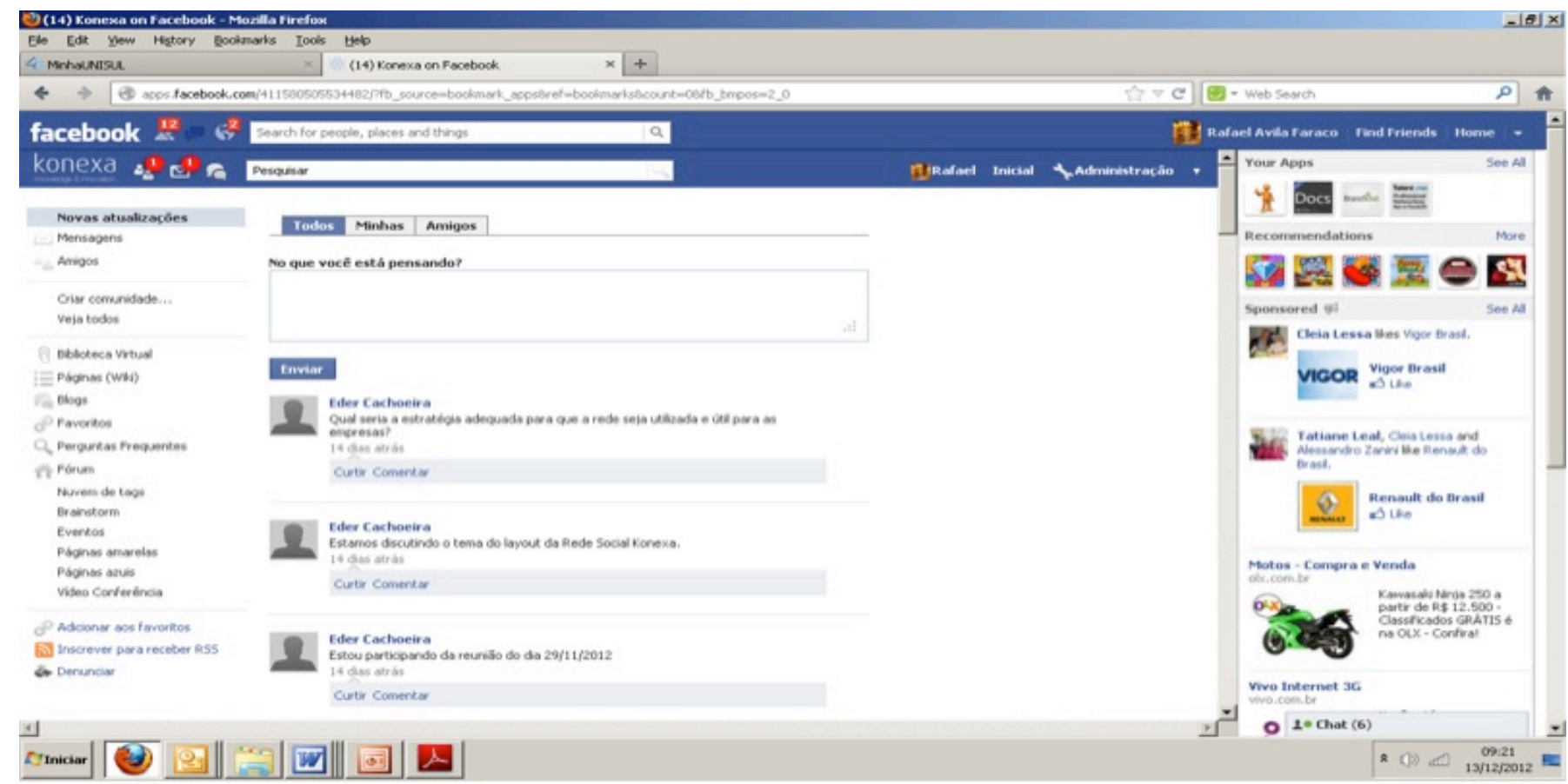

Figure 2 - Main screen of the developed network prototype. Source: screen shot from the Konexa prototype (2013)

ISSN: 07 I8-2724. (http://www.jotmi.org)

Journal of Technology Management \& Innovation (c) Universidad Alberto Hurtado, Facultad de Economía y Negocios. 
The director of the incubator performs service requisitions over coffee - therefore our kitchen area is shared. Forget the incubator where everyone has his own little room, where every room has a sign saying that the sector's operation takes place there. Incubators have to be like this: a room with a group of people, everyone sitting next to each other, because it is there that ideas are often conceived. I had an idea, he had an idea, then suddenly a business idea emerges when my idea is being added to by his idea and from this comes a fusion of ideas. (P5)

As for the identification of the profile of receivers and transmitters of knowledge (category 2) - those who most receive or most offer knowledge on a network - arouses everybody's interest. As regards the identification, recognition and ranking of users, this creates an interesting debate: "As far as I can see, I think that this question of measuring what I give and what I take is important", said one participant (P9). Another (P6) suggested that the members and companies that contribute to the network with the most useful knowledge should be clearly identified and should be able to capitalize on this in terms of their image. It was found that the groups perceive the need to identify the users, and perhaps the companies, which contribute and the way these stakeholders contribute to knowledge on the network. However there was little consensus over the way this information should be published, the use which should be attributed to it or on the way of recognizing and/or rewarding the users.
As regards recognition and/or reward, some participants were opposed to financial rewards and in favor of other forms of recognition such as ranking. This declaration is illustrative:"[...] There, there exists a type of ranking. It is quite a good reward. Suddenly a considerable, respectable amount of business ensues, which is good for the guy who is in the midst of the people there. The network itself, the very people who are saying: this guy really made a contribution, this lad is good." (P8)

Issues related to affinity of profile and formation of relationship networks also predominated in the discourses of the participants, who felt it to be important that the network has mechanisms to bring its members together.These mechanisms should not be limited, according to the declarations, to basic registration information on the network (work area, title), but should also have other information which allows people with common interests to get together.

The context for the transfer of knowledge (category 3) was the highlight of the discussions. The users are clearly concerned that incentives and motivation are generated for everyone to be able to share their knowledge. The following excerpts demonstrate this concern:

The success of the social network lies in spontaneous sharing. If people do not share spontaneously the social network remains stationary. So it has to come from people searching, posting, modifying the content. (P4)

\begin{tabular}{|c|c|}
\hline CATEGORIES AND SUBCATEGORIES & DEFINITIONS \\
\hline $\begin{array}{l}\text { I Types of knowledge } \\
\text { I.I Channels for the transfer of tacit knowl- } \\
\text { edge } \\
\text { I.2 Channels for the transfer of explicit } \\
\text { knowledge }\end{array}$ & $\begin{array}{l}\text { Parts where the participants present their concerns about or interest in } \\
\text { the differences between the type of knowledge to be transmitted, in the } \\
\text { idiosyncrasies of transmission and the process of transferring each type of } \\
\text { knowledge. }\end{array}$ \\
\hline $\begin{array}{l}2 \text { Profile of the receivers and transmitters of } \\
\text { the knowledge } \\
\text { 2.I Identification and ranking } \\
2.2 \text { Relevance of the knowledge transferred }\end{array}$ & $\begin{array}{l}\text { Discourse that demonstrates an interest in the disparity between the offering } \\
\text { of knowledge and its use, concerns with recognition of users, identifying the } \\
\text { flow of knowledge and key-users. }\end{array}$ \\
\hline $\begin{array}{l}\text { 3 Context for the transfer of the knowledge } \\
\text { 3.I Network sharing environment } \\
\text { 3.2 Protection of strategic knowledge }\end{array}$ & $\begin{array}{l}\text { Discourse which contains elements on the environmental conditions that } \\
\text { favor the transfer of knowledge, incentives and motivation to use the virtual } \\
\text { environment and concerns over the protection of strategic knowledge, moni- } \\
\text { toring and usage restrictions. }\end{array}$ \\
\hline $\begin{array}{l}\text { 4 Nature of knowledge transfer } \\
\text { 4.I Characterization and flow of the knowl- } \\
\text { edge }\end{array}$ & $\begin{array}{l}\text { Discourse related to the origin and flow of knowledge (internal or external) } \\
\text { as well as the way it flows across the network. }\end{array}$ \\
\hline 5 Network aims & Comments on the ends for which the proposed network may be used. \\
\hline 6 Tool & General comments about the tool and its interface \\
\hline
\end{tabular}

Table 7 - Analysis categories and subcategories

ISSN: 07I 8-2724. (http://www.jotmi.org)

Journal of Technology Management \& Innovation (c) Universidad Alberto Hurtado, Facultad de Economía y Negocios. 
I believe in the question of motivating individuals to become part of this network and even for companies to get on to these networks. (PI)

Some participants believe that motivation would not be a hindrance when it comes to people in the IT area whose custom it already is to participate actively in discussion groups as well as, when it is perceived that the exchange of knowledge can result in personal and professional benefits, as can be seen below:

This type of public, this type of professional in the area of technology, already has this profile, they already do this and do it naturally, without thinking:"I am not going to help because I'm not going to get anything out of it". These discussion groups are already part of the IT culture. (PI0)

I believe that this will be determined by motivation; the degree of necessity. One example would be the software companies who need to share between them the problem of how to resolve something in Java. It is this unease that will fuel the synergy and see how far it gets you. (P5)

The encouragement to use knowledge transfer networks and the obstacles that may be put in the way of its implementation, are discussed. Amongst these obstacles, besides the motivation to take part, the following were cited: the culture of organizations, striking a balance between passive participation (consuming knowledge) and active participation (offering knowledge), trust when sharing, safety of strategic information. The following statements illustrate some of these issues:

Clearly the majority only go there to consume knowledge and the minority to disseminate it. This is the difficulty I perceive with the Internet. It is not just in the IT area: most people do not generate knowledge, they just consume it. (P3)

Ok: it is still sharing, it is working jointly, great! What does it do for me, what are the issues, how is this network going to guarantee that I am not going to have my idea usurped? "Oh, but people that go there already know this", but then it becomes a question of culture. (P2)

The issue of protection of strategic knowledge stands out as an item for discussion and concern of the participants, as can be seen below:

For the individual taking part in the network, to what extent does he/she have a notion of what is or isn't confidential, or what it is that stimulates partnership? Which bit of your idea is stimulating the partnership and which bit is the "trick up the sleeve", what sets you apart so to speak? That could come back and bite you in the future. That might even act as a bargaining chip - I have this, you have that; let's exchange? I believe that obstacles exist for this sort of thing to flow naturally. (P7)

Aspects related to the nature of knowledge transfer (category 4) were also discussed amongst the participants. This point deals with the origins of the knowledge that is circulating on the network, if it is internal or external to the companies. In this regard, new features were mooted that were not initially anticipated, such as the possibility of the network generating indicators for those partnerships established and the possibility of the network also being used as an intra-organizational tool.

The possible goals of the network were the topic of debate at various moments in sections of the focus group (category 5). This category had not previously been identified; the function of the network is precisely the transfer of knowledge for innovation. The participants see the potential in a social network for the transfer of knowledge with a view to innovation. One of them commented: "the way forward for innovation is open relationships via networks." (PI0). Other accounts substantiate this idea:

Mainly here in the incubator, you have the opportunity to work side by side, communicating with one another. The companies that are doing alright here are those that understood that one hand washes another. I believe that when you talk over a social network with a very specific focus, working this concept of security, that has your details, I believe that it can achieve results. (P7)

This [the network] can strengthen what the market has been demanding more and more in the sense that the market is very competitive and increasingly global. In the past we viewed competition merely as competition. Nowadays competition is partnership in new projects. In this sense, there is today an appetite for this type of situation. (P5)

Nevertheless, the participants themselves were able to see that the system can work to nurture the relationship between companies, create off-line connections, giving rise to innovation and new business. It is supposed that the network serves more to nurture and grow relationships outside the virtual environment.

It is difficult to imagine that a patent might arise out of social networking, but a conversation may emerge from it, an exchange of ideas. It is an environment which has to connect people. (P3)

I believe that these tools, these strategies, contribute to bringing people together and through this, a more formal arrangement may ensue. I believe that this is the proposition: this acceleration of processes. This really helps. (P2) 
Strictly speaking, the issues involving the tool itself (category 6), surfaced when the network prototype was presented. In this sense the talk was mainly about issues, many of which were already anticipated by the prototype, such as: interface, usability, customization, integration with other business tools (e.g. intranet) and other relationship networks.

The results of analyses show that the discourse of the focus group participants reflect the concern with and interest in, not only questions of a more general and broader nature related to the network as a whole (e.g. motivation for use), but also those of a more operational nature (e.g. attributes that should be used for profile affinity). It is interesting to note that this in some way demonstrates and validates the very hierarchy of definitions proposed for the structuring of the network, represented in the present study by assumptions, requirements, features and strategies for use.

\section{Discussion}

Digital social networks have the potential to affect significantly the innovative capacity of organizations. Information, knowledge and sources of knowledge troll these networks potentially generating new understanding. In the context of companies incubated in technological parks, digital social networks may be conceived through planning and may be organized so as to promote the transfer and creation of new knowledge amongst the stakeholders in these parks.

However the effectiveness of digital social networks in transferring knowledge does not only depend on the available technological tools but mostly on motivated players, a recurring issue in the focus group meetings. These players need to see in the network an environment for receiving and transferring knowledge, an environment of cooperative learning which makes it possible to innovate in their activities, generating benefits for the organizations in which they work. When it comes to transfers between organizations, one also has to be aware of other aspects involved in the transfer which could have an impact on perception and the motivation, within the sphere of the organization, to buy into the network and actively participate in it. These aspects are not just technology related, in fact they are predominantly of a cultural and social nature.

This study presents a theoretical structure for a digital social network aimed at supporting the transfer of knowledge between companies that comprise the technology incubators. This structure was developed based on a theoretical review; development of a prototype and its validation in focus group meetings consisting of participants who work in the technology parks in the Brazilian state of Santa Catarina. The proposed structure addresses what has been defined as assumptions, requirements, features and strategies for the use of the network. The theoretical assumptions for the social network are sustained by the following dimensions: the types of knowledge involved in the network (tacit and explicit), the profile of the receivers and transmitters of the knowledge, the transfer environment (context) and the nature of the transfer (internal and/or external). The conditions for these assumptions to be satisfied need to be provided and they consist of the network requirements. For each assumption, this study has presented a set of requirements. So for example, when considering the assumption that both types of knowledge permeate the social network, one of the network requirements is the provision of the means that make it possible to transfer both tacit knowledge and explicit knowledge. In turn, each requirement is composed of a group of features that may be implemented to address it (for example, discussion forums, talent banks, best practice bases, amongst others). Features and the strategies for using these features, i.e. the way in which they may be applied to technology parks, are also provided in this research study.

The participants of the focus group meetings contributed significantly by bringing information that not only allows us to validate what is expected from the developed prototype but also to perfect it. The effectiveness of the focus group methodology should be stressed with regard to the possibility of different individuals exchanging information and knowledge and the richness of the content arising from this exchange.

Generally speaking, the assumptions, requirements, features and strategies for network use have been validated by the focus groups and thus, the following recommendations are normally recommended for a digital social network that is looking to transfer knowledge with the aim of innovation between the members of technology-based companies:

. conception of the network based on four pillars on which the assumptions in this study are founded: (I) types of knowledge; (2) transmitters and receivers of the knowledge; (3) transfer environment and (4) nature of transfer.

- provision of the channels that make the transfer of explicit knowledge and tacit knowledge possible in both formal and informal, personal and impersonal, knowledge transfer environments;

- provision of mechanisms which attempt to encourage the participation of knowledge receivers and transmitters;

. provision of mechanisms that bring together and integrate the participants of the network at an individual and organizational level;

.provision of mechanisms for protecting strategic knowledge. 
The features and strategies recommended in this study will help in the implementation of these recommendations. New features and strategies may be added to them, taking into account the context of the sharing of knowledge between organizations, and the objectives. As a whole, the assumptions, features, requirements and strategies of use outlined in this study may also be used for other studies for validation in contexts similar to the one dealt with here, defining the boundaries for development in the research and conception of digital social networks for the transfer of knowledge and innovation in the business park environment.

\section{References}

ALAVI, M., \& Leidner, D. E. (200I). Review: knowledge management and knowledge management systems: conceptual foundations and research issues. MIS Quarterly, 25(I), 107|36. Retrieved from http://www.jstor.org/stable/325096 |

ALMIRALL, E., \& Casadesus-Masanell, R. (2010). Open Versus Closed Innovation: A Model of Discovery and Divergence. The Academy Of Management Review (AMR), 35(I), 27-47. doi: I0.5465/AMR.20I 0.45577790

BEBENSEE, T., Helms, R., \& Spruit, M. (20I I). Exploring Web 2.0 applications as a means of bolstering up knowledge management. Electronic Journal of Knowledge Management, 9, I-9. Retrieved from http://www.ejkm.com/front/search/index.html

BOEHM, B.W. (1988). A spiral model of software development and enhancement. IEE computer, 6I-72. doi: $10.1109 / 2.59$

BRESCHI, S. (2000). The geography of innovation: a crosssector analysis. Regional Studies, 34(3), 213-229. doi: 10.1080/003434000500I5069

BRÖCHNER, J., Rosander, S., \& Waara, F. (2004). Cross-border post-acquisition knowledge transfer among construction consultants. Construction Management and Economics, 22, 42 I-427. doi: I0.1080/0 | 446 I 9042000240003

CASTELLS, M.A. (2003). The Internet Galaxy: Reflections on the Internet, Business, and Society. New York: Oxford University Press, UK.

COMI, A., \& Eppler, M. J. (20I0). Challenges and solutions for knowledge sharing in inter organizational teams: first experimental results on the positive impact of visualization. In: Proccedings of I-KNOW' 10, I0th International Conference on Knowledge Management and Knowledge Technologies, Graz, Austria.

CORDEY-HAYES, M., \& Gilbert, M. (1996). Understanding the process of knowledge transfer to achieve successful technological innovation. Technovation, I6(16), 30I- 312. doi: 10.1016/0166-4972(96)00012-0

DAVENPORT,T. H., \& Prusak, L. (1998).Working Knowledge: How Organizations Manage What They Know. Boston, MA: Harvard Business School Press.

FARAJ, S., Jarvenpaa, S. L., \& Majchrzak,A. (20II). Knowledge collaboration in online communities. Organization Science, 22(5), I224-1239. Retrieved from http://dx.doi.org/10.1287/ orsc. II $00.06 \mid 4$ 
GUPTA, A. K., \& Govindarajan, V. (2000). Knowledge flows within multinational corporations. Strategic Management Journal, 2I (4), 473-496. doi: I0,I002 / (SICl) 1097-0266 (200004) $21: 4<473$ ::AID-SMJ84> 3.0.CO; 2-I

HACKNEY, R., Desouza, K., \& Loebbecke, C. (2005). Cooperation or competition: knowledge sharing processes in inter-organizational networks. International Conference Knowledge Management, October, 2005, Westin Charlotte, NC, USA. Retrieved from http://www.mtm.uni-koeln. de/team-loebbecke-publications-conf-proceedings/Conf089-2005-Cooperation\%20or\%20Competition-Knowledge\%20Sharing\%20Processes\%20in\%20Inter-Organizational\%20Networks.pdf

HAEFLIGER, S., Monteiro, E., Foray, D., \& von Krogh, G. (20II). Social software and strategy. Long Range Planning, 44, 297-316. doi: I0.1016/j.Irp.201 I.08.00 I

KNUDSEN, M. P. (2007). The relative importance of interfirm relationships and knowledge transfer for new product development success. J. Prod. Innov. Manage., 24(2), I I 7-I38. doi: I0. I I I /j. I540-5885.2007.00238.x

LAHTI, R. K. (2000). Knowledge transfer an management consulting: a look at "the firm". Business Horizons, 3(3), I 10 127. doi: $10.1016 / 50007-6813$ (00) 87389-9

LALKAKA, R. (2002). Technology business incubators to help build an innovation-based economy. Journal of Change Management, 3(2), I67-I76. Available from Business Source Complete, EBSCOhost.

LAM, A. (1997). Embedded Firms, Embedded Knowledge: problems of collaboration and knowledge transfer in global cooperative ventures. Organization Studies, 18(6), 973-996. doi: I0.1 I77/0I7084069701800604

LAWSON, B., Petersen, K. J., Cousins, P. D. \& Handfield, R. B. (2009). Knowledge sharing in interorganizational product development teams: the effect of formal and informal socialization mechanisms. J Prod InnovManag, 26, I56-172. doi: |0. I I | I/j. I540-5885.2009.00343.x

MATIN, H. Z., Alvani, S. M., Jandaghi, G. R., \& Pashazadeh, Y. (20I0). Designing and clarifying knowledge sharing model in administrative agencies to improve the performance. European Journal of Economics, Finance and Administrative Sciences, 22. Available from http://www.researchgate.net

MCGRATH, R. G., Tsai, MH.,Venkataraman, S., \& MacMillan, IC. (1996). Innovation, competitive advantage and rent: a model and test. Management Science, 42(3), 389-403. Retrieved from http://www.jstor.org/stable/2634350
MINAYO, M. C. S. (2000). O desafio do conhecimento: pesquisa qualitativa em saúde. São Paulo: Hucitec; Rio de Janeiro: Abrasco.

NONAKA, I., \& Takeuchi, H. (1995).The Knowledge-creating Company: How Japanese Companies Create the Dynamics of Innovation. Oxford University Press, UK.

O'DELL, C., \& Grayson, C.J. (1998). If only we knew what we know: identification and transfer of internal best practices. California Management Review, 40(3), I54-174. Available from Business Source Complete, EBSCOhost.

O'HEOCHA, C., Wang, X., \& Conboy, K. (20I2). The use of focus groups in complex and pressurised IS studies and evaluation using Klein \& Myers principles for interpretive research. Information Systems Journal, 22, 235-256. doi: I0.1 III/j. I365-2575.20I I.00387.x

PORTER, M. E. (1998). On Competition. Boston: Harvard Business School Press.

ROMIJN, H., \& Albu, M. (2002). Innovation, networking and proximity: high technology firms in the UK. Regional Studies, 36 (I), 8I-86. doi : 10.1080/00343400I20099889

SAUNDERS, M., Lewis, P., \& Thornhill, A. (2009). Research methods for business students. England: Pearson Education Limited.

SOMMERVILLE, I (2004). Software Engineering. Essex, UK.

TEECE, D. (2000). Strategies for managing knowledge assets: the role of firm structure and industrial context. Long Range Planning, 33(I), 35-54. doi: 10.1016/S0024-630I (99) 00II7$X$

TONET. H. C., \& Paz, M. G. T. (2006). Um modelo para o compartilhamento de conhecimento no trabalho. Revista de Administração Contemporânea, 10 (2). Retrieved from http://dx.doi.org/I0.1590/SI4I 5-65552006000200005

VITO, A., Garavello, A. C., \& Schiuma, G. (1999). Knowledge transfer and interfirmrelationship in industrial districts: the role of the leader firm. Technovation, 19,53-63. doi: 10.1016/ SO I66-4972(98)00078-9

VON KROGH, G. (20I2). How does social software change knowledge management? Toward a strategic research agenda. Journal of Strategic Information Systems, 2 I, I54- I64. doi: 10.1016/j.jsis.2012.04.003 